Finance and Economics Discussion Series Divisions of Research \& Statistics and Monetary Affairs Federal Reserve Board, Washington, D.C.

\title{
Estimating Capacity Utilization from Survey Data
}

\section{Norman Morin and John Stevens \\ 2004-49}

NOTE: Staff working papers in the Finance and Economics Discussion Series (FEDS) are preliminary materials circulated to stimulate discussion and critical comment. The analysis and conclusions set forth are those of the authors and do not indicate concurrence by other members of the research staff or the Board of Governors. References in publications to the Finance and Economics Discussion Series (other than acknowledgement) should be cleared with the author(s) to protect the tentative character of these papers. 


\title{
Estimating Capacity Utilization from Survey Data
}

\author{
Norman Morin \\ Federal Reserve Board \\ John Stevens \\ Federal Reserve Board
}

August 2004

\begin{abstract}
$\underline{\text { Abstract }}$
In this paper, we review the history and concepts behind the Federal Reserve's measures of capacity and capacity utilization, summarize the methods used to construct the measures, and describe the principal source data for these measures - the Census Bureau's Survey of Plant Capacity. We show that the aggregate manufacturing utilization rate from the Survey of Plant Capacity does not exhibit the "cyclical bias" possessed by utilization rates from the less statistically rigorous utilization rate surveys previously used to estimate the Federal Reserve's measures. At the detailed industry level, utilization rates from the Survey of Plant Capacity for several industries do appear to possess a cyclical bias, but we demonstrate that this bias is removed in the construction of the Federal Reserve capacity measures. We further show that the Federal Reserve measures, by combining the Census survey utilization rates with other indicators of capacity, do not discard significant information contained in the Census rates. In fact, the Federal Reserve procedures add to the predictive content of the Census utilization rates in models of capital spending, capacity expansion, and changes in price inflation.
\end{abstract}

JEL codes: D24, E22, E31.

We would like to thank Carol Corrado and Joyce Zickler for helpful comments and suggestions. The opinions expressed here are those of the authors and not necessarily those of the Board of Governors of the Federal Reserve System or its staff. 


\section{Introduction}

The amount of resource slack in the economy is closely watched by policymakers, academics, and industry analysts. The Federal Reserve publishes monthly estimates of capacity utilization that have long been used to help analyze developments in the industrial sector. Aggregate measures of utilization are constructed from detailed industry-level utilization rates that are themselves often used to reveal potential industrylevel bottlenecks. These measures of capacity utilization are used to signal emerging supply chain problems, to forecast investment by manufacturers, and to assess the likelihood of an acceleration or deceleration in inflation.

The estimates produced by the Federal Reserve reflect a methodology that has been continuously refined over nearly 50 years. Since 1990, the principal data source used by the Federal Reserve to construct estimates of manufacturing capacity has been the Survey of Plant Capacity (SPC) conducted by the United States Census Bureau. ${ }^{1}$ The Census Bureau and the Federal Reserve have adopted an economic definition of capacity that assumes the full employment of all variable factors of production and the use of only the equipment in place and ready to operate. ${ }^{2}$ This definition, made more precise later, captures the key aspects of capacity utilization that are thought to be useful for analyzing prices, capital spending, and industry bottlenecks.

The Federal Reserve's measures build upon the SPC rates in two key ways. First, the Federal Reserve attempts to remove statistical noise that arises from sampling error. For a given industry, the Federal Reserve calculates an initial capacity index by dividing the Federal Reserve's index of industrial production (IP) by the corresponding SPC utilization rate. Because these series are from different data sources, whose coverage and construction may differ, part of the annual movement of their ratio may simply reflect measurement error. The Federal Reserve's final capacity indexes combine these initial capacity indexes with other indicators of capacity that are suggested by economic theory and consistent with the definition of capacity described above. Only that part of the initial capacity indexes related to the other measures of capacity expansion is

\footnotetext{
${ }^{1}$ The Survey of Plant Capacity began in 1974 and is jointly funded by the Federal Reserve Board and the Department of Defense.

${ }^{2}$ See Corrado and Mattey (1997) and Forest (1979) for more detailed discussions of the economic underpinnings of the various definitions of capacity.
} 
incorporated into the final estimates, and as a result, the noise in the initial capacity indexes is removed. Second, the Federal Reserve sharpens the signal from the SPC measures by bringing other information to bear, such as a knowledge of changes in the SPC survey questions; changes in the sample construction for the SPC; and capacity information in physical units from other sources. Thus, the Federal Reserve's estimation procedures in no way reflect shortcomings of the SPC, but rather represent an analytical exercise that is not possible when simply tabulating survey responses.

In the past, some observers have argued that survey-based utilization rates tend to have less cyclical amplitude than would be suggested by other, more direct, estimates of capacity, including surveys that directly ask about capacity rather than utilization (demonstrated initially by Perry, 1973). ${ }^{3}$ Consequently, if utilization rates vary less over the business cycle, then a capacity index directly constructed from those rates will exhibit more cyclical variability than would be suggested by other indicators of capacity, such as industry capital spending patterns or physical estimates of capacity, would suggest (as utilization rates appear in the denominator). We test the cyclicality of capacity indexes constructed using the SPC and the Federal Reserve Board (FRB) utilization rates over the past 30 years, and find that neither measure is excessively cyclical at the aggregate level. At the detailed industry level, however, we find that for a several industries, capacity indexes constructed directly from SPC utilization rates exhibit excess cyclicality, but this excess movement is removed by the Federal Reserve's methodology. The risk, of course, is that the Federal Reserve removes too much information. We cannot test this possibility directly, as the Federal Reserve also adds information, but we can test the net effect of the Federal Reserve's methodology by examining the ability of both sets of utilization rates to predict capital spending, future capacity expansions, and prices.

A brief history of capacity measurement at the Federal Reserve is provided in the next section. In section 3 we provide details on the SPC, and in section 4 we walk through the methodology used by the Federal Reserve to combine the SPC data with other indicators of capacity change. Section 5 analyzes the cyclical properties of the SPC and FRB utilization rates, and tests whether the refinements of and additions to the SPC rates results in any net loss of useful information.

\footnotetext{
${ }^{3}$ Also see Raddock and Forest (1976), Christiano (1981), and Schnader (1984).
} 


\section{A brief history of the Federal Reserve capacity and capacity utilization measures}

Indexes of output and capacity were first developed by the Board's staff during the economic expansion in the mid-1950s (see Raddock, 1987). These early estimates covered several major manufactured materials. The major materials indexes were based on measures of physical volume from government and trade sources, and were used internally to analyze current business conditions, primarily inflationary pressures and the demand for capital goods. In the 1960s, the Federal Reserve maintained separate measures of capacity and utilization for manufacturing and for selected industrial materials. Unlike the unpublished major materials index, however, the published estimates for manufacturing were not constructed from physical volume data. The manufacturing capacity indexes were instead based on end-of-year utilization rates from the McGraw-Hill survey of capacity utilization that were divided into December values of the Federal Reserve's indexes of production. ${ }^{4}$ The year-to-year changes in these implied capacity estimates were then refined using alternative indicators of capacity expansion, such as a measure of gross capital stocks, and linearly interpolated to the quarterly frequency. ${ }^{5}$

Periodically throughout the 1970s and 1980s, the detail covered by the manufacturing indexes and the materials indexes was expanded, and in 1983, the scope of coverage was widened to include mining and utilities. ${ }^{6}$ Utilization rates from the new Survey of Plant Capacity (SPC) from the Bureau of the Census, which started in 1974, began to be incorporated into the Federal Reserve estimates.

In 1990, the publication of the capacity and capacity utilization figures were combined into a single statistical release with the industrial production indexes. The

\footnotetext{
${ }^{4}$ McGraw-Hill, Inc. (later its DRI subsidiary) collected annual data on both utilization rates and on capacity expansion from a sample of large companies each December from 1954 to 1988.

${ }^{5}$ Typically, the logarithm of the ratio of an industry's implied capacity to its capital stock-a capital productivity measure - was regressed on a series of deterministic trends and dummy variables; implicitly, the model assumed a unit elasticity of capacity with respect to the stock of capital, an assumption that was relaxed in 1997. A similar model was run using the logarithm of the ratio of implied capacity to the capacity index directly asked about in the McGraw-Hill survey. The annual estimate of Federal Reserve capacity was the average of the fitted values from the two models.

${ }^{6}$ The new monthly Federal Reserve statistical release (G.3), "Capacity Utilization," began in January 1977 and included monthly utilization rates, as well as quarterly data for output, capacity, and utilization for manufacturing and industrial materials (and their major component series).
} 
1990 capacity revision, described in the June 1990 Federal Reserve Bulletin (Raddock, 1990), created an integrated and more detailed system of output, capacity, and capacity utilization measures for total industry and for a variety of industry sub-aggregates. This move resulted in several changes to the overall capacity system. Most importantly, the materials system was discontinued as a separate entity; the primary source of utilization rates for manufacturing industries became the Bureau of the Census's Survey of Plant Capacity; and the number of detailed industry-level measures in manufacturing was more than doubled to 54 individual series.

Further revisions to the capacity system in the 1990s maintained the structure introduced in the 1990 revision. Individual series were occasionally added or eliminated to reflect changes in the related production indexes, and several technical improvements were introduced.

The capital measures that are used as alternative measures of capacity expansion were further refined in 1995 to reflect the flow of services derived from the net stocks of productive assets (Raddock 1996). The measures - known as capital input or capital services - are rental-price-, or user-cost-, weighted indexes of the asset-level net capital stocks; that is, the indexes weight growth rates in the net stocks of individual assets by an estimate of that asset's share of the aggregate marginal product of the industry's capital. In 1997, the regression models that relate SPC-based implied capacities to alternative indicators of capacity expansion (see footnote 4 ) were made more flexible by relaxing the restriction of a unit elasticity on the capital measure (Gilbert, Morin, and Raddock, 2000). ${ }^{7}$

In December of 2002, the Federal Reserve issued a comprehensive revision of industrial production, capacity, and capacity utilization whose primary purpose was to reclassify the detailed industry structure of production and capacity from the Standard

\footnotetext{
${ }^{7}$ Two additional refinements to the construction of capacity were introduced in 1999 and described in the March 2000 Bulletin. First, a new interpolation procedure was introduced to form monthly time series of capacity based on the fourth-quarter baseline capacity estimates produced by the regression models. The new procedure allowed capacity growth rates to change smoothly over time instead of imposing a constant growth rate throughout the year, while maintaining the same fourth-quarter to fourth-quarter growth rates calculated under the old procedure. Second, the models that relate SPC-based implied capacity to alternative indicators of capacity were expanded to include variables that capture the age profile of the capital stock. In several studies, age variables have been used to better capture the effect of technological change.
} 
Industrial Classification (SIC) system to the North American Industry Classification System (NAICS). ${ }^{8}$ The reclassification changed industry details a bit but left the overall industry coverage of the capacity system essentially unchanged. As of the 2002 comprehensive revision, the capacity system included 85 individual series - a mix of 3-, 4- and 6-digit NAICS industries - of which 67 are in manufacturing, 16 in mining, and 2 in utilities.

In addition to the Federal Reserve, a number of groups have, at various points in time, published indexes of capacity and capacity utilization. ${ }^{9}$ In the early 1980 s there were seven separate capacity and utilization measures that covered the manufacturing sector. These measures included the annual estimates from McGraw-Hill and the fourthquarter SPC measures from the Census Bureau, both of which served as source data for the FRB estimates. Quarterly estimates were published by the BEA, Wharton Econometric Forecasting Associates (WEFA), and Rinfret Associates (see Schnader, 1984 for a detailed discussion of the various measures). Currently, the only long-running survey-based measure of capacity utilization with broad industry coverage is the SPC; the Institute for Supply Management (or ISM, formerly the National Association of Purchasing Management, or NAPM) has published semiannual estimates of manufacturing utilization rates since November $1990{ }^{10}$ Narrower measures for specific industries are produced by various government and trade groups, often in terms of physical units (such raw steel capability from the American Iron and Steel Institute).

\footnotetext{
${ }^{8}$ This undertaking, which involved mapping numerous data sources (including plant-level micro-data) from SIC to NAICS, is documented in Corrado (2003) as well as a series of papers: Bayard and Klimek (2003), Morin (2003), and Stevens (2003).

${ }^{9}$ Even considering just a single plant, there exists a range of definitions of capacity. "Engineering capacity" is the most uncomplicated notion of capacity - the maximum level of output when operating the existing machinery at the peak possible linespeed nearly 24 hours per day, 7 days per week with only minimal downtime. Conversely, capacity may refer the plant manager's "preferred capacity," a unit costminimizing level or profit-maximizing level of output, which, except for a few specific industries, is likely to be noticeably lower than the engineering maximum. In between is the concept of "full production" capacity, in which capacity is the level at which all variable inputs are used at the maximum level, without consideration of the rising materials, labor, and other costs that would undoubtedly be present as output exceeded preferred capacity. Furthermore, one set of assumptions may be appropriate to answer questions about inflationary pressures or industry bottlenecks and another for mobilizing resources in wartime.

${ }^{10}$ The Institute for Supply Management (ISM) surveys about 400 firms and is not a statistical sample, although the distribution of companies surveyed roughly corresponds to the relative composition of two-digit SIC industries.
} 


\section{The Survey of Plant Capacity}

The Survey of Plant Capacity (SPC) is now the primary source for the annual utilization rates used to construct the monthly capacity and capacity utilization rate measures for manufacturing industries. The SPC, a mandatory survey that is jointly sponsored by the Federal Reserve Board and the Department of Defense, measures fourth-quarter rates of capacity utilization for about 17,000 manufacturing plants at the 6-digit NAICS industry level. ${ }^{11}$ The SPC began with a "mini-survey" in 1973 of 4000 plants that covered the fourth quarters of 1973 and 1972. The full survey began in 1974 with a sample of about 9000 plants, and was conducted annually until 1988. From 1990 to 1996 , the survey was conducted biannually, but each survey collected two years worth of information. For the 1995-1996 survey, the sample size was expanded to the current size of about 17,000 plants. Since 1997, the survey has been conducted annually with this larger sample size.

In the 2002 SPC survey form, the instructions to plant managers for estimating full production capability were:

Full Production Capability - The maximum level of production that this establishment could reasonably expect to attain under normal and realistic operating conditions fully utilizing the machinery and equipment in place. In estimating market value at full production capability, consider the following

- $\quad$ Assume only the machinery and equipment in place and ready to operate will be utilized. Do not include facilities or equipment that would require extensive reconditioning before they can be made operable.

- $\quad$ Assume normal downtime, maintenance, repair, and cleanup. If full production requires additional shifts or hours of operation, then appropriate downtime should be considered in the estimate.

- $\quad$ Assume labor, materials, utilities, etc. are fully available.

\footnotetext{
${ }^{11}$ The 2002 Census of Manufacturers recorded 344,000 plants (down about 20,000 from the 1997 Census), so the SPC sample represents about 5 percent of manufacturing establishments. However, because large plants are included in the sample with certainty, the establishments surveyed by the SPC account for a touch over 50 percent of manufacturing shipments.
} 
- $\quad$ Assume number of shifts, hours of plant operations, and overtime pay that can be sustained under normal conditions and a realistic work schedule.

- Assume a product mix that was typical or representative of your production during the fourth quarter. If your plant is subject to short-run variation assume the product mix of the current period.

- Do not assume increased use of productive facilities outside the plant for services (such as contracting out subassembly work) in excess of the proportion that would be normal during the fourth quarter.

The SPC is a statistical survey. A new probability sample for the SPC is drawn every five years from the Census of Manufactures; the 2004 SPC will be the first year of a new sample drawn from the 2002 Census. Each industry is treated independently, and, based on the Tille sampling procedure (Slanta, 2003), establishments are selected with a "probability proportionate to size;" industries denoted as "priority industries" by the Department of Defense are sampled more heavily. Census staff follow up on nonresponses with additional mailings or phone calls, and final response rates are around 80 percent. Preliminary survey results are published around October, and final SPC results are normally published in January; revisions are usually minimal. The sample is augmented annually to reflect new plant births.

In 1999, the SPC began to be published on a NAICS basis, and this transition in classification schemes affected the SPC sample in two significant ways: Both logging and the publishing piece of "printing and publishing" left the NAICS-based manufacturing sector. However, the Federal Reserve's definition of the industrial sector did not change, and at the request of Federal Reserve Board, the Census Bureau agreed to continue sampling publishers; because presently the sample is drawn from the Census of Service Industries. Unfortunately, because logging is now under the purview of the Department of Agriculture, the Census Bureau was not able to continue sampling firms in this industry.

The SPC has implemented three significant changes since 1974. First, in 1982 respondents were requested to complete the survey form even if the plant was idle (but not permanently closed) during the fourth quarter. Presumably, before 1982, the SPC 
undercounted idled plants, and, consequently, reported industry-level utilization rates that were higher in downturns than would otherwise have been the case (although this has been difficult to detect statistically).

Second, before the 1989-1990 survey, plant managers were asked about their "preferred level of operation" and "practical capacity"; now the survey asks for the level of "full production" and "national emergency production." However, the definitions of "preferred level of operation" and "full production" appear close enough that they are treated as a single time series without any ad hoc adjustments. ${ }^{12}$

Finally, in addition to the large sample expansion with the 1995-1996 survey, the survey implemented a change to the assumptions about plant shifts. In surveys before the 1995-1996 SPC, the respondent was instructed to determine capacity hours and shifts by using the maximum level attained in the last five years; since then, the respondent is allowed to assume extra shifts at capacity: "If full production requires additional shifts or hours of operation, then appropriate downtime should be considered in the estimate" (bold italics added). This suggests that if the five year moving maximum of shifts and hours that was used before 1995 is less than what a plant manger would have chosen unconstrained, then the reported level of capacity before 1995 was lower than it would have been under the newer instructions; therefore, all else equal, one would expect that utilization rates should have exhibit a discrete downward shift in 1995. This shift is observed in the data; at the manufacturing level, the discrete shift appears about 4 percentage points. $^{13}$

In addition to answering questions about actual production, full production capability, and national emergency production capability, managers report other useful information. For example, managers report reasons for changes in full production capability relative to the fourth quarter a year earlier. Reasons include:

- $\quad$ capital expenditures

- $\quad$ capital retirements

- $\quad$ price changed but product mix is the same

\footnotetext{
12 Doyle (2000) showed that, using plant level data, the Federal Reserve's assumption overlaying of preferred utilization rates from the pre-1989 surveys and full production rates from the surveys for the 1989-1994 period is not rejected by the data.

${ }^{13}$ In principle, the downward shift in rates can be decomposed into an effect due to the wording change and to the sample expansion. We plan to explore this issue further using the microdata from the SPC at the Census Bureau's Center for Economic Studies.
} 
- $\quad$ change in method of operation

- $\quad$ change in product mix or product specifications

- change in material input

Managers also provide reasons for operating at less than 100 percent of their full production capability in the fourth quarter. Reasons include:

- $\quad$ Not most profitable to operate at full production capability

- Insufficient supply of materials

- Insufficient orders

- Insufficient supply of local labor force/skills

- $\quad$ Lack of sufficient fuel or electric energy

- $\quad$ Equipment limitations

- $\quad$ Storage limitations

- Logistics/transportation constraints

Managers indicate the minimum time that would be required to ramp up production to both full and national emergency production levels.

The survey also collects information on shift-work patterns. The data on the workweek of capital has been used by researchers to investigate the procyclicality of productivity and capital utilization. ${ }^{14}$ The survey asks plant managers for

- Days per week in operation

- $\quad$ Plant hours per week in operation

- Weeks in operation in the quarter

- Total number of production workers

- $\quad$ Hours worked by temporary production workers

- $\quad$ Overtime hours worked by production workers

- Total number of temporary production workers

- Total hours worked by production workers

The SPC and other surveys of utilization rates may yield significantly different utilization rates for a given industry as a result of important differences in the degree of the specificity of the survey's definition of capacity, the sampling unit (plant or firm), the sample size, and the industry composition of the sample. For example, the establishmentbased rates in the SPC are substantially lower than the rates for the same industry in the ISM survey of firms, whose sample includes companies with multiple establishments. Between 1990 and 2002 the aggregate SPC rates for manufacturing averaged about

\footnotetext{
${ }^{14}$ See, for example, Mattey and Strongin (1995), Beaulieu and Mattey (1996), and Shaprio (1996).
} 
10 percentage points lower than the operating rates from the ISM. Multi-establishment companies presumably take into account intrafirm bottlenecks that limit the overall capacity of the firm, whereas the respondents to the Survey of Plant Capacity only consider the maximum output of their own establishment (see Bureau of the Census, 1983). ${ }^{15}$

\section{Constructing the Federal Reserve estimates of capacity and capacity utilization}

The Federal Reserve constructs capacity indexes and utilization rates that completely cover the industrial sector (manufacturing, mining, and electric and gas utilities) and that are consistent with the Federal Reserve measures of industrial production. Estimates for industry aggregates, such as manufacturing, are constructed by combining the individual series. Six general steps are involved in calculating the utilization rates published by the Federal Reserve:

\section{Step 1: Construct preliminary implied capacity indexes}

The first step in producing a capacity index is to divide the Federal Reserve production index for the industry by a benchmark utilization rate- both are typically either fourth-quarter or end-of-year estimates. The implied capacity index $\left(I C A P_{t}\right)$ for period $t$ is:

$$
I C A P_{t}=I P_{t} / U_{t}{ }^{16}
$$

and, like the production index, is expressed as a percentage of output in a base year. For about 90 percent for manufacturing capacity, the Survey of Plant Capacity provides the utilization rate for denominator of (1.1).

The implied capacity estimates in (1.1) provide the general trend movements of capacity as well as initial estimates of the levels that are consistent with the Federal Reserve production indexes. For example, if the production index for an industry has

\footnotetext{
${ }^{15}$ Moreover, once one moves beyond a single plant, the practical maximum output of an industry is typically less than the sum of the individual capacities of the constituent plants; although an individual plant may produce at its maximum possible rate, all plants attempting simultaneously to produce at capacity may induce supply bottlenecks for critical inputs, and factor price increases might make producing at capacity infeasible. By similar reasoning, the capacity for the manufacturing sector is clearly less than the sum of industry-level capacities.

${ }^{16}$ For example, if the production index in the fourth quarter of 2002 is 120 (120 percent of the average of 1997 production) and the related utilization rate is 80 percent, the implied capacity index for 2002 is $120 / 0.8=150.0$.
} 
been roughly constant while the survey-based utilization rates have risen, then the implied capacity index would trend down.

\section{Step 2: Relate the implied capacity estimates to alternative indicators of capacity}

Although a capacity index published by the Federal Reserve derives its level and trend movements from the implied capacity index, the annual changes in capacity are determined by additional information on the economic determinants of capacity expansion. The Federal Reserve uses regression-based procedures to combine these additional measures with the SPC utilization rates. The purpose of the regressions is to ensure that the year-to-year changes in the published estimates of capacity conform to movements in the alternative determinants of capacity change. For about 90 percent of manufacturing industries, the principal alternative indicator is a measure of industry capital input. Relating the implied capacity indexes to these other measures removes from the implied capacity index the part of the year-to-year movements that appears to be measurement or sampling error-related noise and that does not appear to represent actual changes in an industry's productive capacity.

The refined estimates of annual capacity are the fitted values of the regression of implied capacity on industry capital input $\left(K_{t}\right)$; a deterministic trend $(t)$; dummy variables for outliers, level shifts and trend breaks $\left(D_{i t}\right)$; and on a variable related to the average age of the capital stock, $A_{t}{ }^{17}$

$$
\log \left(I C A P_{t}\right)=\alpha_{o}+\alpha_{1} t+\beta \log \left(K_{t}\right)+\gamma \log \left(A_{t}\right)+\sum_{i} \delta_{i} D_{i t}+v_{t}
$$

or, where the lower case letters represent natural logarithms,

$$
\operatorname{icap}_{t}=\alpha_{o}+\alpha_{1} t+\beta k_{t}+\gamma a_{t}+\sum_{i} \delta_{i} D_{i t}+v_{t}
$$

A principal result from the regression-based procedure is that the coefficients of the capacity regression determine the relationship between capital productivity - the ratio of capacity and capital input - and the determinants of capacity. Rewriting (1.2) in terms of

\footnotetext{
${ }^{17}$ The age variable is the ratio of the age of an industry's capital stock relative to its expected service life, given the mix of assets that compose the stock. This measure represents the portion of the aggregate life of a given mix of assets that has been used up. In several studies, age variables have been used to capture the effect of embodied technological change - the idea that productivity augmenting technological change is vintage specific, that is, it is embodied in the design of new equipment and structures, rather than affecting all existing inputs in the production process.
} 
capital productivity yields

$$
\text { icap }_{t}-k_{t}=\alpha_{o}+\alpha_{1} t+(\beta-1) k_{t}+\gamma a_{t}+\sum_{i} \delta_{i} D_{i t}+v_{t} .
$$

Equation (1.4) shows that one can represent the model-based capacity estimates as the sum of the contributions of capital input and capital productivity, where capital productivity embodies the combined effects of total factor productivity, labor at capacity (such as the work period of capital at capacity), and capital deepening. ${ }^{18}$

In short, the trend in a published industry-level capacity index is derived primarily from the trend in the industry's implied capacity index, and the annual changes in the capacity index reflect changes in the flow of services derived from the industry's stock of capital. Although the capacity indexes that are the fitted values of (1.2) are generally procyclical — following the cycles in capital spending - they do not fluctuate as much as the preliminary implied capacity indexes, either at an annual frequency or at a business-cycle frequency.

\section{Step 3: Interpolate the annual estimates to a monthly frequency}

The end-of-year or fourth-quarter capacity estimates (depending on data source) for the 85 individual component series are interpolated to a monthly frequency. Given fourth-quarter target levels for each year, monthly rates of change are constructed via a cubic interpolation that allows monthly rates of change to evolve smoothly.

\section{Step 4: Apply annual capability adjustments}

The Federal Reserve Board's estimates of capacity attempt both to capture the concept of sustainable maximum output and to produce estimates of capacity utilization that are historically consistent, so that a given utilization rate in the present implies about the same degree of slack as in the past. The other government sources or private trade groups from which capacity estimates are derived, however, do not necessarily use a

\footnotetext{
${ }^{18}$ In a simple constant returns to scale model of capacity as a function of capital $(k)$, labor at capacity $\left(L_{C}\right)$, and total factor productivity $(A), Q_{C, t}=A_{t} K_{t}^{\alpha} L_{C, t}^{1-\alpha}$, or, where lower case letters represent the natural logarithms of the variables, the model is $q_{C, t}=a_{t}+\alpha k_{t}+(1-\alpha) l_{C, t}$. The log of capital productivity is then $\pi_{t}=q_{C, t}-k_{t}=a_{t}+(\alpha-1) k_{t}+(1-\alpha) l_{C, t}$, which can be rewritten as $\pi_{t}=a_{t}-(1-\alpha)\left(l_{C, t}-k_{t}\right)$. This represents capital productivity as proportional to total factor productivity and inversely related to capital deepening, which is determined by labor at capacity and capital.
} 
uniform definition of capacity, and their figures may be based on a different concepts of capacity. The Federal Reserve produces a correction factor - the annual capability adjustment - to minimize the effects of these definitional differences. In particular, this correction factor reduces the level of capacity for industries whose estimates appear to be based on short-term peaks or on an engineering concept rather than on an estimate of sustainable maximum output. ${ }^{19}$

Second, an adjustment is made for historical continuity. Most utilization rates for the manufacturing sector were based on the McGraw-Hill utilization rate survey, which, after 34 years, was discontinued in 1988. In the years that the company-based McGrawHill and establishment-based Survey of Plant Capacity overlapped (1974-1988), the McGraw-Hill utilization rate for an industry generally possessed a significantly higher mean than the operating rate for the same industry from the Survey of Plant Capacity. After the demise of the McGraw-Hill survey, the Survey of Plant Capacity became the principal source of manufacturing utilization rates, and the annual capability adjustments to capacity were adjusted to maintain roughly the same average utilization rate over the period in which the two surveys overlapped.

\section{Step 5: Construct aggregate series}

The aggregation of capacity and capacity utilization rates presents distinct issues compared with the aggregation of individual production indexes, as capacity and utilization are constructed and defined in relation to industrial production. ${ }^{20}$ An annual utilization aggregate is calculated as

$$
U_{A t}=\Sigma_{i \in A} P_{i t} I_{i t} / \Sigma_{i \in A} P_{i t} C_{i t}=\Sigma_{i \in A}\left(P_{i t} C_{i t}\right) U_{i t} / \Sigma_{i \in A} P_{i t} C_{i t},
$$

where $I$ is the industry-level production index, $P$ is industry-level unit value-added, $C$ is the capacity index, and $U$ is the annual utilization rate. Thus, the aggregate annual utilization rates are equivalent to capacity-weighted aggregates of individual utilization rates; that is, they are a combination of the individual utilization rates weighted by

\footnotetext{
${ }^{19}$ The adjustment is particularly large for electricity generation, where up to one third of generating capacity is reserved to meet peak summer demand, and, in addition, where a considerable amount of capacity is kept as a safety margin. Much of this capacity is not sufficiently efficient to run on a consistent basis, and is excluded from the Federal Reserve estimate of sustainable output.

${ }^{20}$ The Federal Reserve Bulletin article by Corrado, Gilbert, and Raddock (1997) describes the aggregation of capacity and capacity utilization in much greater detail.
} 
proportions that reflect the individual's share in the aggregate current value of production at capacity.

Monthly capacity aggregates are constructed in three steps:

- Utilization aggregates are calculated on an annual basis through the most recent full year as in (1.5).

- The annual aggregate capacity index is derived by dividing the corresponding production index by the utilization aggregate.

- The monthly aggregate capacity index is obtained by interpolating the annual capacity index from the previous step with a Fisher index of its constituent monthly capacity series. For the very recent period, since the most recent full year, each monthly capacity aggregate is extrapolated by this same Fisher index, adjusted by a factor that accounts for the differences in their relative growth rates. $^{21}$

Step 6. Construct aggregate utilization rates

Aggregate utilization rates are calculated by dividing the appropriate production index by the related capacity index.

\section{The cyclical and explanatory properties of Federal Reserve capacity indexes}

The Federal Reserve Board (FRB) and the Census Bureau's Survey of Plant Capacity (SPC) are currently the only sources for lengthy time series of detailed industry-level utilization rates. ${ }^{22}$ As discussed earlier, utilization rates from previous long-running surveys—-specifically, from the BEA and McGraw Hill— possessed less cyclical amplitude than other, more direct measures of capacity would imply (Perry,

\footnotetext{
${ }^{21}$ As shown by the steps above, capacity aggregates are not simply annually weighted Fisher indexes of the individual capacity series. If a capacity aggregate were to be formulated in a way similar to that of a production aggregate and if a utilization aggregate were calculated as a ratio of the two separately aggregated series, then a noticeable distortion in this utilization aggregate would occur if: (1) the relative price of a component industry changes significantly, and (2) the utilization rate of the component differs from the average of the group.

${ }^{22}$ The industry-level FRB rates generally begin in 1972, with many series extending back considerably farther, and the SPC rates begin in 1974. The Institute for Supply Management has published an aggregate manufacturing utilization rate semiannually since November 1990.
} 
1973; Christiano, 1981). Given an index of production, damped cyclical amplitude for utilization rates mechanically implies capacity indexes that exhibit greater cyclical movements than could be explained by capital spending patterns and changes in the capital stock. Indeed, at the industry level, the survey-based implied capacity measures often implied contractions of capacity in recessions that appeared implausible, and this "lost" capacity was soon "found" as the economy recovered. ${ }^{23}$ The excess cyclicality may represent either a cyclical bias in the implied capacity indexes or a cyclical bias in the alternative indicators of capacity expansion. As discussed below, both forms of this bias will result in a positive correlation between changes in capacity and changes in production (even after conditioning on alternative measures of capacity expansion and controlling for endogeneity problems).

We look at the cyclicality of the FRB and SPC capacity indexes for both aggregate manufacturing and for the 213 -digit NAICS manufacturing industries. The fourth-quarter manufacturing utilization rates and corresponding capacity indexes from the FRB and SPC are shown in figure 1. At the aggregate manufacturing level, we find no statistical evidence of a cyclical bias in either the FRB or SPC capacity indexes. At the detailed industry level, several SPC indexes appear to exhibit a cyclical bias, but this apparent bias does not show through to the FRB indexes. If the bias is due to mismeasurement of the alternative indicators of capacity expansion, then removing it results in a loss of information content. However, because the Federal Reserve's capacity methodology also brings other information to bear - such as knowledge about changes in SPC methodology - the net effect on the relative information content in the FRB indexes is ultimately an empirical question. Our results show that the net effect is to boost the power of the FRB indexes (relative to the SPC indexes) to predict series that capacity utilization is usually expected to influence-industry investment spending, capacity growth, and industry prices. The data appendix includes details about the sources and construction of all the data used in the models below.

\footnotetext{
${ }^{23}$ This lost-and-found capacity may be the result of the respondents being more likely in a downturn than in an upturn to exclude the marginal plant and equipment from their appraisal of capacity or, if the survey is at the firm level, more likely to exclude temporarily idled facilities from the calculation of capacity.
} 


\section{Cycles in FRB rates and SPC rates}

Table 1 shows that aggregate SPC utilization rates possess less cyclical amplitude than the FRB utilization rates. In the six trough-to-peak and peak-to-trough episodes since 1974, only in the 1994 to 2002 period did the SPC rates move more - both in terms of percentage points or in terms of standard deviations. In the other five episodes, the SPC rates moved at least 0.9 percentage points less than the FRB rates; and in those episodes the average difference was 2.1 percentage points, or 0.7 standard deviation, smaller. In the most recent period, the difference between FRB and SPC rates is greatly reduced if the estimated combined effect of the 1995-1996 sample expansion and change in the SPC instructions is removed from the SPC utilization rates.

Below, we investigate the cyclical properties of the FRB and SPC utilization rates and implied capacity indexes using the basic procedures employed by Perry (1973).

\section{The difference between FRB and SPC capacity indexes}

The FRB capacity index for most industries is derived from the fitted values of (1.2), where the implied capacity index is the ratio of the Federal Reserve production index for the industry divided by the SPC utilization rate. Apart from level differences (for historical continuity), the difference between the logarithms of the FRB and SPC capacity indexes should, therefore, roughly be the residuals from the regression in (1.2). ${ }^{24}$ The difference series, then, should embody the information contained in the SPC that is discarded by the FRB capacity indexes as a result of the modeling procedure. For each industry in the table, the model used is

$$
c_{t}^{F R B}-c_{t}^{S P C}=\alpha_{0}+\alpha_{1} \Delta q_{t}+\alpha_{2} D U M 95^{+}+v_{t}
$$

where $c^{i}$ is the logarithm of capacity and $i=\mathrm{FRB}$ or SPC; $\Delta q$ is a fourth-quarter over fourth-quarter measure of instrumented output (the fitted values of the differenced-log of the industry's production index regressed on the differenced logarithm of production worker hours, the unemployment rate, and the diff-log of real GDP); and $v$ is an error

\footnotetext{
${ }^{24}$ The difference, $c_{t}{ }^{F R B}-c_{t}^{S P C}$, will not be precisely the residuals from the actual capacity models employed in the construction of the FRB capacity indexes because the published FRB capacity indexes are constructed at a significantly finer level of detail (65 NAICS manufacturing industries) and the capacity indexes for about 10 percent of manufacturing capacity are based on data in physical units from trade sources.
} 
that follows an AR(1) process. The regressions also include a level-shift dummy variable to account for the 1995-1996 change in the Census survey. The production measure is instrumented because implied capacity is defined as production divided by utilization, and as a result, regressing the changes in implied capacity on changes in production would very likely suffer from the production index being correlated with the error in the implied capacity index.

If an FRB capacity index does not exhibit excess cyclicality, but the SPC measure does show more cyclicality than expected, then the difference between the FRB and SPC measures should be significantly negatively related to current output.

The results are displayed in table 2. The difference between the FRB and SPC capacity indexes is negatively related to output in all but three cases. At the aggregate manufacturing level, however, the cyclical measure is insignificant, which implies that the difference between FRB and SPC capacity indexes is likely merely noise (apart from a positive constant related to the FRB measures retaining historical continuity with the McGraw Hill survey). However, at the detailed industry level, the difference between the FRB capacity indexes and the SPC capacity indexes is significant for 5 of 21 industries (at a 5 percent significance level).

The results suggest that a handful of SPC implied capacity indexes display more cyclicality than the corresponding FRB capacity indexes. However, these results are silent on whether the explanation is that the FRB indexes show no excess cyclicality, while a subset of SPC capacity indexes possess excess cyclicality; or if nearly all SPC indexes are cyclically biased, but the FRB indexes, which are derived, in part from SPC utilization rates, inherit the cyclicality of the SPC rates. These possibilities are investigated below.

\section{Cycles in FRB and SPC capacity indexes}

A capacity index is considered to exhibit cyclical bias if there is a statistically significant positive relationship between capacity and output after controlling for the relationship between capacity and capital input.

The model used for examining the cyclicality of the capacity indexes is:

$$
\Delta c_{t}^{i}=\alpha_{o}+\alpha_{1} \Delta q_{t}+\alpha_{2} \Delta k_{t}+v_{t},
$$


where, in addition to the variables defined above, $k$ is a measure of year-end industry capital input. As shown in table 3, at the aggregate manufacturing level, neither the FRB nor the SPC measures exhibit a significant and positive relationship between the change in capacity and the change in output. Differences emerge, however, at a more detailed industry level. Although FRB capacity indexes show a significant relationship with output in only two industries (one at the 1 percent level and one at just the 10 percent level), the SPC implied capacity indexes show a statistically significant and positive relationship between changes in capacity growth and changes in output (at the 5 percent level) in just over half of the industries. As Perry (1973) wrote in the context of the McGraw-Hill survey, "since the variation in the capital stock should capture much of the true variation in capacity, it is extremely doubtful that this relation between output and capacity represents a genuine case of rising output inducing capacity growth." Instead, the most likely explanation, under Perry's interpretation, is a cyclical bias yielding "lost-and-found" capacity in some of the detailed SPC-based indexes.

An alternative explanation lies in the mismeasurement of changes in capital input. If the measured percent change in capital input is too large in recessions (due, for instance, to a counter-cyclical scrappage rate that is not accounted for in the construction of the underlying capital stock measures) and too low in expansions (due to the level of the capital stock being too high at the end of a recession from mismeasured scrappage), then we might find a spurious relationship between changes in capacity and changes in production. In effect, production changes proxy for the countercyclical scrappage. Note, however, that mismeasurement of capital input can also work in the other direction if asset depreciation rates are procyclical (i.e., when output levels are high, the equipment is worked more intensively and depreciates more rapidly, and therefore measures of capital with a fixed age-efficiency profile would be too procyclical); the FRB methodology assumes a depreciation rate that is independent of the business cycle. The net effect of cyclicality in scrappage or depreciation is not known, so we can only raise these possibilities as caveats to keep in mind when interpreting our results on cyclical bias.

In summary, neither the capacity index for aggregate manufacturing utilization based on SPC rates nor the published FRB manufacturing capacity index exhibit a significant degree of excess cyclicality. Moreover, at the detailed industry level, while a 
handful of SPC utilization rates appear to imply capacity indexes that possess excess cyclicality, the corresponding FRB capacity indexes, derived by combining data from the SPC with information on industry capital spending, do not exhibit excess cyclicality. If the excess cyclicality is due to mismeasurement of capital input, then removing this cyclicality from the SPC also removes valuable information from the FRB indexes. However, the FRB indexes incorporate other information beyond the SPC utilization rates, including the measures of capital; information on changes in SPC sample construction; information on changes in the SPC questionnaire; data on capacity in physical units from trade and government sources; and dummy variables to account for outliers and level- or trend-shifts. The net impact of removing from the implied capacity indexes cyclicality in those individual series in which it exists; of removing what would appear to be measurement error from the SPC; and including in the FRB measures the additional information related to capital input, survey changes, and so on, is an empirical question that hinges whether the ability of the FRB utilization rates to predict movements in series that are of interest to policymakers and analysts - such as future industry capital spending, price inflation, and capacity expansion — has been augmented or reduced relative to the utilization rates from the SPC.

\section{Predicting industry investment}

To describe the value of utilization rates as measures of slack, economists point to their ability to help predict capital spending and explain price pressures. We now investigate whether the FRB methodology adds to the ability of SPC rates to explain movements in these variables.

First, we compare the power of FRB and SPC utilization rates to explain changes in industry investment. The model is

$$
\Delta I_{t}=\alpha_{0}+\alpha_{1} \Delta I_{t-1}+\alpha_{2} I K_{t-1}+\beta U_{t-1}^{i}+\varepsilon_{t}
$$

where $I$ is industry investment spending (chain-weighted, annual average), $I K$ is the ratio of current dollar industry investment to the lag of industry current cost capital stock (annual average investment divided by end-of-year capital from the prior year), and $U^{i}$ is the FRB or SPC utilization rate for the fourth quarter. The Census Bureau's Census of Manufactures and Annual Survey of Manufactures are the sources for the annual current- 
dollar investment data, which are chain aggregated using BEA investment deflators. See the data appendix for more detail on the construction of the investment and capital series. The investment and capital variables are included to control for investment relative to a long-run investment/capital ratio. The model is initially estimated excluding the utilization measures, and the first two columns of numbers in table 4 show the increase in the R-squared obtained by including the lagged utilization measures. The two columns on the right display the $t$-statistics on the lagged utilization rate measures.

After controlling for the investment/capital ratio and lagged investment, the lagged FRB and SPC utilization rates possess significant explanatory power for well over half of the industries. At the manufacturing level, the utilization rates are significant at the 1 percent level, and, for both the FRB and SPC rates, a one percent increase in manufacturing utilization rates, all else equals, leads to a 1.5 percent increase in capital spending the following year. Comparing the FRB and SPC results, the FRB rates are significant in every case in which SPC rates are significant, and the increment to the $\mathrm{R}$-squared is greater for the SPC rate in only 5 out of the 21 industries. The coefficient estimates possess the wrong sign in only a couple instances.

Thus, for predicting the change in industry investment, the construction of the FRB measures has not discarded important information contained in the SPC utilization rates. If anything, the net effect of the Federal Reserve's methodology is to add information to the measures of utilization.

The exercise is repeated for the investment/capital ratio (which is more directly related to the change in the stock of capital) using the same framework:

$$
I K_{t}=\alpha_{0}+\alpha_{1} \Delta I_{t-1}+\alpha_{2} I K_{t-1}+\beta U_{t-1}^{i}+\varepsilon_{t}
$$

As shown in table 5, once again both sets of utilization rates possess significant explanatory power for capital spending at the manufacturing level; they are significant at the 1 percent level. At the industry level, both sets of rates are significant in nearly all industries, and both sets rarely have the wrong sign. In all but four cases, the FRB rates increase the R-squared measures relative to regressions excluding utilization rates by more than the SPC rates. Again, the FRB rates do not appear to discard important information contained in the SPC utilization rates relevant for explaining movements in capital spending. 


\section{Predicting capacity growth}

The largest difference between the FRB measures of capacity and utilization and the SPC-based measures is in their ability to explain future changes in capacity. One would expect, all else equal, that high utilization rates would be a signal to increase capacity. Table 6 displays the results of regressing the change in FRB capacity and SPCbased implied capacity on lagged utilization rates and lagged production increases. The model estimated is:

$$
\Delta c_{t}^{i}=\alpha_{0}+\alpha_{1} \Delta i p_{t-1}+\alpha_{2} U_{t-1}^{i}+\varepsilon_{t}
$$

where ip is the Federal Reserve production index for the industry, and all the variables are fourth-quarter values.

In nearly every case, lagged utilization rates are significant predictors of future additions to capacity for the FRB measures. For overall manufacturing and manufacturing excluding high-tech industries, a one percentage point increase in fourthquarter FRB utilization rates leads to about a 0.15 percent increase in capacity the following year. Conversely, the lagged SPC-based utilization rates are significant in fewer than one-half of the industries. The dramatically reduced significance in the SPCbased models likely arises from the combined effects of noisier dependent variables (the SPC-based implied capacity indexes) and less cyclically sensitive regressors (the SPC operating rates). One exception is beverage and tobacco products, where the SPC rate is significant at the 10 percent level, while the FRB rate is insignificant.

\section{Predicting industry prices}

Finally, lagged FRB and SPC utilization rates prove reasonably useful as predictors of changes in industry-specific price inflation. Changes in inflation are examined rather than levels of inflation, as Phillips curve-type models that are estimated with changes in inflation yield an estimate of the non-accelerating inflation capacity utilization (NAICU) rate.

The hurdle is fairly high for utilization rates to be useful predictors of prices, as the model also includes momentum terms (lagged changes in industry price inflation), proxies for supply shocks (changes in energy price inflation), and changes in industry 
wage inflation. The regression model is:

$$
\Delta \pi_{t}=\alpha_{0}+\alpha_{1} \Delta \pi_{t-1}+\alpha_{2} \Delta \pi_{t-1}^{\text {energy }}+\alpha_{3} \Delta \pi_{t-1}^{\text {wages }}+\beta U_{t-1}^{i}+\varepsilon_{t}
$$

where $\pi$ is the rate of change of the price of industry output (therefore $\Delta \pi$ is the change

in inflation), $\pi^{\text {energy }}$ is the producer price index for energy, and $\pi^{\text {wages }}$ is the rate of change in industry wages; all are annual averages. The data sources and methods are described in the data appendix.

As shown in table 7, lagged FRB utilization rates are significant at least at the 10 percent level in more than half of the industries, although utilization rates register the wrong sign in 6 cases (and in one, the coefficient is significant at the 10 percent level). SPC utilization rates are significant at the 10 percent level in only 4 cases, and the estimated coefficients have the wrong sign in more cases than the FRB rates. SPC rates, however, perform better in the model for nonmetallic minerals, where the FRB utilization rates are not significant. The FRB modeling procedure that combines SPC utilization rates and information on industry capital spending significantly improves the explanatory power of utilization rates in these simple price equations.

\section{Conclusion}

This paper reviewed the concepts underlying the Federal Reserve measures of capacity and capacity utilization, their history, and the methods used to construct them. The Census Bureau's Survey of Plant Capacity (SPC), the only current long-running and broadly based survey of utilization rates, was discussed in detail. The aggregate manufacturing utilization rates from the Census Bureau do not appear to be insufficiently cyclical, and therefore a capacity index derived by dividing a manufacturing production measure by the aggregate SPC utilization series does not possess what Perry (1973) called a cyclical bias. Cyclical bias had previously been shown to be a feature of surveybased rates from earlier vintages of government and industry utilization surveys; capacity tended to be "lost" in recessions and "found" quickly as industry recovered.

At the detailed industry-level, however, a cyclical bias is found in the SPC data for several industries. In contrast, Federal Reserve capacity measures, which combine survey-based information from the Census Bureau and from alternative indicators of 
capacity, such as measures of industry capital input, are shown not to possess a cyclical bias.

Utilization rates from both the Census Bureau and the Federal Reserve are shown to be excellent predictors of industry capital spending. The Census Bureau measures are generally less successful at predicting future capacity expansion and changes in industry price inflation, while the Federal Reserve measures perform reasonably well in both cases. In sum, while the Federal Reserve's estimation method successfully removes the cyclical bias found in the implied capacity indexes for several industries, it does so without removing from the Census measures useful information for explaining movements in industry capital spending, capacity expansion, and changes in industry price inflation. Moreover, the Federal Reserve measures typically perform better than the SPC measures in these exercises. As a result, the regression-based procedure employed by the Federal Reserve to combine the SPC-based utilization rates with other information, principally measures of industry capital, appears, on net, to add information content to the measures capacity utilization published in the very useful Survey of Plant Capacity. 


\section{References}

Bacharach, M.B. (1965). "Estimating Nonnegative Matrices from Marginal Data," International Economic Review, Vol. 6, pp. 294-310.

Bayard, Kimberly and Shawn Klimek (2003), "Reclassifying the Census of Manufactures from the Standard North American Classification System to the North American Classification System, 1963 to 1992," 2003 Proceedings of the American Statistical Association, Business and Economics Statistics Section, Alexandria, VA.

Beaulieu, J. Joseph and Joe Mattey (1998), “The Workweek of Capital and Capital Utilization in Manufacturing," Journal of Productivity Analysis, vol. 10, pp. 199-223.

Bureau of the Census (1982), "Survey of Plant Capacity, 1981," Current Industrial Reports, MQ-Cl(81)-1

Bureau of the Census (1983), "Survey of Plant Capacity, 1982," Current Industrial Reports, MQ-Cl(82)-1.

Bureau of the Census (1992), "Survey of Plant Capacity, 1990” Current Industrial Reports, MQ-Cl(90)-1.

Bureau of the Census (1997), "Survey of Plant Capacity, 1996” Current Industrial Reports, MQ-Cl(96).

Bureau of Labor Statistics (1983). "Trends in Multifactor Productivity, 1948-1981,” BLS Bulletin No. 2178.

Christiano, Lawrence J. (1981), "A Survey of Measures of Capacity Utilization,” International Monetary Fund Staff Papers, pp. 144-199.

Corrado, Carol A., Charles E. Gilbert, and Richard D. Raddock (1997), "Industrial Production and Capacity Utilization: Historical Revision and Recent Developments," Federal Reserve Bulletin, v89, pp. 67-92.

Corrado, Carol A., (2003), "Industrial Production and Capacity Utilization: The 2002 Historical and Annual Revision," Federal Reserve Bulletin, v83, pp. 151-176.

Corrado, Carol, and Joe Mattey (1997). "Capacity Utilization,” Journal of Economic Perspectives, Vol. 11, No. 1 (Winter), pp. 151-167. 
De Leeauw, Frank (1979), "Why Capacity Utilization Rates Differ," Measures of Capacity Utilization: Problems and Tasks, Federal Reserve Board of Governors, Staff Study 105.

Doyle, Maura P. (2000) "The 1989 Change in the Definition of Capacity: A Plant-Level Perspective," U.S. Census Bureau, Center for Economic Studies Working Paper CES-WP-00-09.

Forest, Lawrence R., Jr. (1979), “Capacity Utilization: Concepts and Measurement," Measures of Capacity Utilization: Problems and Tasks, Federal Reserve Board of Governors, Staff Study 105.

Gilbert, Charles C., and Michael F. Mohr (1996), "Capital Stock Estimates for Manufacturing Industries: Methods and Data," Board of Governors of the Federal Reserve System working paper.

Gilbert, Charles C., Norman J. Morin, and Richard D. Raddock (2000), "Industrial Production and Capacity Utilization: Recent Developments and the 1999 Annual Revision," Federal Reserve Bulletin, v86, pp.188-205.

Morin, Norman J. (2003), "NAICS and the 2002 Historical Revision of Industrial Production, Capacity, and Capacity Utilization 2003 Proceedings of the American Statistical Association, Business and Economics Statistics Section, Alexandria, VA.

Raddock, Richard D. (1987), "Federal Reserve Estimates of Capacity and Capacity Utilization," Industrial Capacity: Major Issues and National Security Implications, conference volume.

Raddock, Richard D. (1990), "Recent Developments in Industrial Capacity and Utilization," Federal Reserve Bulletin, v76, pp.411-435.

Raddock, Richard D. (1995), "A Revision to Industrial Production and Capacity Utilization, 1991-1995," Federal Reserve Bulletin, v81, pp.16-25.

Raddock, Richard D. and Lawrence R. Forest (1976), "New Estimates of Capacity Utilization: Manufacturing and Materials," Federal Reserve Bulletin, v62, pp. 892-905.

Perry, George L. (1973), “Capacity in Manufacturing,” Brookings Papers on Economic Activity, Vol. 3, 701 - 742.

Schnader, Marjorie H. (1984), "Capacity Utilization," Handbook of Economic and Financial Measures, Dow Jones-Irwin: Homewood IL, 74-104.

Shapiro, Matthew D. (1996), "Macroeconomic Implications of Variations in the 
Workweek of Capital," Brookings Papers on Economic Activity, Vol. 2, pp. 79119.

Slanta, John (2003), “Tillé Sampling in a Nutshell," Census Bureau Memorandum, Manufacturing Programs Methodology Branch.

Stevens, John J. (2003), “Overhauling Industrial Production: The 2002 Annual Revision," 2003 Proceedings of the American Statistical Association, Business and Economics Statistics Section, Alexandria, VA. 


\section{Data Appendix}

Utilization rates: The Survey of Plant Capacity (SPC) from the Bureau of the Census collects utilization rate data at the 4-digit SIC (from 1974 to 1996) and 6-digit NAICS level (from 1997 on). The SPC utilization rate data on a 6-digit NAICS basis were aggregated to the 3-digit NAICS level using value-added weights from the Annual Survey of Manufacturers (ASM) and Census of Manufactures (COM). The SPC data on a 4-digit SIC basis were converted to the 6-digit NAICS level as shown in Morin (2003) using the variable share mapping from Bayard and Klimek (2003). The resulting 6-digit NAICS data were aggregated to the 3-digit NAICS level as above.

Nominal investment: ASM/COM data on capital expenditures on new equipment and structures are compiled at the 4-digit SIC through 1996. From 1997, data were compiled on total capital expenditures on equipment and on structures at the 6-digit NAICS industry levels. The SIC-based capital data on a 4-digit SIC basis were converted to the 6-digit NAICS level using the variable share mapping from Bayard and Klimek (2003).

Real investment: Real investment measures require estimating real industry-by-asset investment and aggregating these data to the industry level with asset-specific price deflators (see Mohr and Gilbert, 1996, for details). This is performed in four steps. First, US-level asset totals are taken from the BEA NIPA data. Second, industry-level investment totals are taken from the ASM/COM; Third, given the estimates of total investment by each manufacturing industry (and total US excluding manufacturing) and the total US investment in each asset category, industry-by-asset investment is estimated using the biproportional matrix balancing (or RASing) technique of Bacharach (1965); the initial estimates of the asset distribution of industry investment were taken from the roughly quinquennial Capital Flows Tables (CFT) of the BEA. ${ }^{25}$ The industry-level real

\footnotetext{
${ }^{25}$ Given row (asset investment) and column (industry investment) totals that sum to the same value; nonnegativity constraints on investment; and an initial guess on the asset allocation of industry investment, the RASing procedure converges to a unique industry-by-asset investment flow. For the years a CFT exists, it is used as the initial guess for the RASing procedure; for years between CFTs, a linear interpolation of the adjacent CFTs are used; for years after the most recent CFT, the final allocation from the previous year is
} 
investment measures are Fisher chain-weighted aggregates of the asset-level investment flows.

Capital stocks: Industry-level net capital stocks are constructed as a Fisher index of the industry-by-asset capital stocks, where the weights are the asset-specific prices (see BLS, 1983). Industry-by-asset capital stocks are constructed using the perpetual inventory model system (PIMS) methodology (see BLS, 1983, and Mohr and Gilbert, 1996). Each asset is assigned a specific age-efficiency profile that describes the proportion of its original efficiency that remains in each period as the asset ages. ${ }^{26}$ For a given industry, the capital stock in a particular asset category is a weighted sum of all past investment flows, where the weights are given by the age-efficiency profile.

Current-cost capital stocks: The replacement cost, in current dollars, of the net capital stock is constructed by taking the real capital stock levels for each asset category, multiplying them by the asset price deflators for that year, and summing to the industry level.

Capital input: Industry-level capital input measures estimate the potential flow of services derived from the net capital stocks in the various asset categories. They are constructed as a Tornqvist index of the industry-by-asset capital stocks where the weights are the asset-specific rental prices or user costs (see BLS, 1983). The rental price for a particular asset, $p(r+\delta-\dot{p} / p) \tau$, is the marginal product of that asset, where $p$ is the asset price, $r$ is a required rate of return, $\delta$ is a depreciation rate, and $\tau$ is a tax term (see BLS, 1983).

Industry wages: Industry wages are constructed by dividing the industry wage bill for production workers by production worker hours for the industry, both taken from the ASM/COM. The data were collected at the 4-digit SIC through 1996. From 1997, data

used as the initial guess for the current year; for years before the first CFT, the final allocation from the following year is used as the initial guess.

${ }^{26}$ The age efficiency profile is based on integrating over all possible asset service lives given a stochastic mean service life and standard deviation (for asset discards) and a hyperbolic beta-decay function (for asset decay). See Mohr and Gilbert (1996) for details. 
were compiled at the 6-digit NAICS levels. The SIC-based data were converted to the 6-digit NAICS level using the variable share mapping from Bayard and Klimek (2003).

Industry output prices: The industry prices are derived by chain-aggregating detailed shipments deflators from the BEA gross output by industry data system. The detailed SIC-based data were classified on a NAICS basis using the shares derived by Bayard and Klimek (2003). 
Table 1. Peak-to-trough and Trough-to-Peak Changes in Manufacturing Utilization Rates

\begin{tabular}{c|cc|cc}
\hline & \multicolumn{2}{|c|}{ Change in utilization rates } & \multicolumn{2}{c}{$\begin{array}{c}\text { Change in standardized } \\
\text { utilization rates }\end{array}$} \\
\cline { 2 - 5 } & FRB & SPC & FRB & SPC \\
\hline $1974-1978$ & 5.7 & 4.0 & 1.5 & .9 \\
$1978-1982$ & -17.4 & -16.5 & -4.4 & -3.8 \\
$1982-1988$ & 16.2 & 14.7 & 4.1 & 3.4 \\
$1988-1991$ & -6.2 & -2.4 & -1.6 & -.6 \\
$1991-1994$ & 5.3 & 2.5 & 1.3 & .6 \\
$1994-2002$ & -10.7 & -16.0 & -2.7 & -3.7 \\
$1994-2002$ & -10.7 & $-11.3 * *$ & -2.7 & $-2.6^{* *}$ \\
\hline
\end{tabular}

Notes:

The first two columns show the change between the fourth quarters of the years indicated in percentage points. The two columns on the right show the change between the fourth quarters of the years indicated in terms of standard deviations of the respective utilization rates.

The starred entries remove the estimated effect of the sample expansion and change in instructions that began in the 1995-1996 SPC survey. The effect was estimated by a regression of the SPC utilization rates on a constant, change in manufacturing IP, a dummy variable that was 1 from 1995 through 2002, and an AR(1) error; the effect of the dummy variable was removed from the series. 
Table 2. Explaining the Movements of the Ratio of FRB Capacity and SPC Capacity with Production and Capital Input

\begin{tabular}{|c|c|c|}
\hline NAICS & Industry & $\begin{array}{c}\text { Coefficient } \\
\text { on } \Delta q\end{array}$ \\
\hline & Manufacturing & -.08 \\
\hline & Excluding high-tech industries & -.08 \\
\hline 311 & Food & -.53 \\
\hline 312 & Beverage and tobacco & $-.64 *$ \\
\hline 313 & Textile mills & .03 \\
\hline 314 & Textile product mills & $-.29 * *$ \\
\hline 315 & Apparel & $-.67 * * *$ \\
\hline 316 & Leather & $-.27 *$ \\
\hline 321 & Wood products & -.01 \\
\hline 322 & Paper & .00 \\
\hline 323 & Printing & $-.41 *$ \\
\hline 324 & Petroleum and coal products & -.19 \\
\hline 325 & Chemicals & $-.32 *$ \\
\hline 326 & Plastics and rubber products & $-.32 * * *$ \\
\hline 327 & Nonmetallic minerals & -.15 \\
\hline 331 & Primary metals & $-.19 * * *$ \\
\hline 332 & Fabricated metal products & -.02 \\
\hline 333 & Machinery & $-.11 * *$ \\
\hline 334 & Computer and electronic product & -.11 \\
\hline 335 & Electrical equipment and appliances & $-.12 *$ \\
\hline 336 & Transportation equipment & .06 \\
\hline 337 & Furniture & -.02 \\
\hline 339 & Miscellaneous manufacturing & -.40 \\
\hline
\end{tabular}

Notes:

Regressions run from 1974 to 2002.

* significant at the 10 percent level, ** significant at the 5 percent level, ${ }^{* * *}$ significant at the 1 percent level.

The high-technology industries include computers, communications equipment, and semiconductors (NAICS 3341, 3342, 334412-9). 
Table 3. Explaining the Change In Capacity with the Change in Production

\begin{tabular}{|c|c|c|c|}
\hline \multirow[b]{2}{*}{ NAICS } & \multirow[b]{2}{*}{ Industry } & \multicolumn{2}{|c|}{ Coefficient on $\Delta q$} \\
\hline & & FRB & SPC \\
\hline & Manufacturing & -.01 & .07 \\
\hline & $\begin{array}{l}\text { Excluding high-tech } \\
\text { industries }\end{array}$ & -.02 & .03 \\
\hline 311 & Food & -.00 & $1.14 *$ \\
\hline 312 & Beverage and tobacco & -.02 & .81 \\
\hline 313 & Textile mills & $.08 * * *$ & $.35^{*}$ \\
\hline 314 & Textile product mills & .02 & $.49 * *$ \\
\hline 315 & Apparel & -.01 & $.89 * *$ \\
\hline 316 & Leather & .00 & $.65^{* * *}$ \\
\hline 321 & Wood products & .01 & .09 \\
\hline 322 & Paper & .10 & .13 \\
\hline 323 & Printing & .11 & $.74 * *$ \\
\hline 324 & Petroleum and coal products & .21 & $.86^{* *}$ \\
\hline 325 & Chemicals & .02 & .20 \\
\hline 326 & Plastics and rubber products & -.06 & $.31 * *$ \\
\hline 327 & Nonmetallic minerals & -.01 & $.16^{*}$ \\
\hline 331 & Primary metals & -.03 & $.22^{* *}$ \\
\hline 332 & Fabricated metal products & .00 & .02 \\
\hline 333 & Machinery & -.02 & $.22 * *$ \\
\hline 334 & $\begin{array}{l}\text { Computer and electronic } \\
\text { product }\end{array}$ & .03 & $.34 * * *$ \\
\hline 335 & $\begin{array}{l}\text { Electrical equip. and } \\
\text { appliances }\end{array}$ & -.01 & $.21 * *$ \\
\hline 336 & Transportation equipment & -.01 & .09 \\
\hline 337 & Furniture & .00 & $.31 * *$ \\
\hline 339 & Miscellaneous manufacturing & $-.23^{*}$ & .19 \\
\hline
\end{tabular}

Notes:

Regressions run from 1974 to 2002.

* significant at the 10 percent level, ** significant at the 5 percent level, *** significant at the 1 percent level.

The high-technology industries include computers, communications equipment, and semiconductors (NAICS 3341, 3342, 334412-9). 
Table 4. Predicting Industry-level Investment by Lagged Utilization Rates

\begin{tabular}{ll|rr|rc}
\hline \multirow{2}{*}{ NAICS } & Industry & \multicolumn{2}{|c|}{$\begin{array}{c}\text { Increment to } \\
\text { R-squared }\end{array}$} & \multicolumn{2}{c}{$\begin{array}{c}t \text {-statistic on } \\
\text { lagged utilization }\end{array}$} \\
\cline { 3 - 6 } & Manufacturing & FRB & SPC & FRB & SPC \\
\hline & $\quad$ Excluding high-tech & 32.4 & 29.1 & $3.6^{* * *}$ & $3.3^{* * *}$ \\
311 & industries & 34.1 & 32.9 & $3.7^{* * *}$ & $3.6^{* * *}$ \\
312 & Food & 1.0 & 3.1 & .5 & .9 \\
313 & Beverage and tobacco & .0 & 2.0 & .0 & -.7 \\
314 & Textile mills & 23.0 & 11.2 & $3.1^{* * *}$ & $2.0^{* *}$ \\
315 & Textile product mills & 1.8 & .7 & .8 & .5 \\
316 & Apparel & 7.8 & 5.7 & 1.6 & 1.3 \\
321 & Leather & 24.5 & 20.5 & $2.9^{* * *}$ & $2.6^{* *}$ \\
322 & Wood products & 28.3 & 20.6 & $3.6^{* * *}$ & $2.9^{* * *}$ \\
323 & Paper & 32.0 & 40.7 & $3.6^{* * *}$ & $4.4^{* * *}$ \\
324 & Printing & 6.8 & 6.2 & 1.5 & 1.4 \\
325 & Petroleum and coal products & 2.1 & 3.4 & -.8 & 1.1 \\
326 & Phemicals & 24.3 & 19.5 & $3.1^{* * *}$ & $2.6^{* *}$ \\
327 & Nontics and rubber products & 31.6 & 24.0 & $4.7^{* * *}$ & $3.7^{* * *}$ \\
331 & Primary metals & 32.2 & 17.1 & $3.6^{* * *}$ & $2.3^{* *}$ \\
332 & Fabricated metal products & 25.8 & 19.3 & $3.0^{* * *}$ & $2.5^{* *}$ \\
333 & Machinery & 23.9 & 22.4 & $2.8^{* * *}$ & $2.7^{* *}$ \\
334 & Computer and electronic & 54.4 & 36.4 & $5.6^{* * *}$ & $3.8^{* * *}$ \\
335 & product & 11.8 & 6.8 & $1.9^{*}$ & 1.4 \\
336 & alectrical equipment and & 27.8 & 15.8 & $3.5^{* * *}$ & $2.4^{* *}$ \\
337 & Transportation equipment & 6.0 & 6.2 & 1.5 & 1.5 \\
339 & Furniture & 6.1 & 4.2 & 1.6 & 1.3 \\
\hline & Miscellaneous manufacturing & 11.6 & .3 & $2.0^{*}$ & -.3 \\
\hline & & & & &
\end{tabular}

Notes:

Regressions run from 1974 to 2001.

* significant at the 10 percent level, ** significant at the 5 percent level, ${ }^{* * *}$ significant at the 1 percent level.

The high-technology industries include computers, communications equipment, and semiconductors (NAICS 3341, 3342, 334412-9). 
Table 5. Predicting Industry-level Investment/Capital Ratios by Lagged Utilization Rates

\begin{tabular}{|c|c|c|c|c|c|}
\hline \multirow[b]{2}{*}{ NAICS } & \multirow[b]{2}{*}{ Industry } & \multicolumn{2}{|c|}{$\begin{array}{l}\text { Increment to } \\
\text { R-squared }\end{array}$} & \multicolumn{2}{|c|}{$\begin{array}{c}t \text {-statistic on } \\
\text { lagged utilization }\end{array}$} \\
\hline & & FRB & SPC & FRB & $\overline{\mathrm{SPC}}$ \\
\hline & Manufacturing & 16.9 & 16.3 & $4.1 * * *$ & $4.0 * * *$ \\
\hline & $\begin{array}{l}\text { Excluding high-tech } \\
\text { industries }\end{array}$ & 15.2 & 14.9 & $4.3 * * *$ & $4.2 * * *$ \\
\hline 311 & Food & 2.1 & 2.4 & 1.0 & 1.1 \\
\hline 312 & Beverage and tobacco & .0 & .2 & -.1 & -.6 \\
\hline 313 & Textile mills & 22.6 & 12.3 & $3.5 * * *$ & $2.3 * *$ \\
\hline 314 & Textile product mills & 6.7 & 4.4 & 1.4 & 1.1 \\
\hline 315 & Apparel & 4.5 & 5.8 & 1.5 & 1.7 \\
\hline 316 & Leather & 11.2 & 7.5 & $2.9 * * *$ & $2.2 * *$ \\
\hline 321 & Wood products & 15.1 & 10.7 & $4.2 * * *$ & $3.2 * * *$ \\
\hline 322 & Paper & 10.0 & 12.3 & $4.0 * * *$ & $4.9 * * *$ \\
\hline 323 & Printing & 10.5 & 6.1 & $2.1 * *$ & 1.6 \\
\hline 324 & Petroleum and coal products & .9 & .9 & -.9 & .8 \\
\hline 325 & Chemicals & 4.6 & 4.1 & $3.4 * * *$ & $3.2 * * *$ \\
\hline 326 & Plastics and rubber products & 36.3 & 32.1 & $4.8 * * *$ & $4.3 * * *$ \\
\hline 327 & Nonmetallic minerals & 11.9 & 6.6 & $3.6 * * *$ & $2.4 * * *$ \\
\hline 331 & Primary metals & 7.9 & 6.1 & $3.2 * * *$ & $2.7 * * *$ \\
\hline 332 & Fabricated metal products & 9.5 & 8.4 & $3.4 * * *$ & $3.1 * * *$ \\
\hline 333 & Machinery & 10.0 & 6.5 & $5.1 * * *$ & $3.5^{* * *}$ \\
\hline 334 & $\begin{array}{l}\text { Computer and electronic } \\
\text { product }\end{array}$ & 10.1 & 6.1 & $2.8 * * *$ & $2.1 * *$ \\
\hline 335 & $\begin{array}{l}\text { Electrical equipment and } \\
\text { appliances }\end{array}$ & 27.0 & 17.2 & $3.9 * * *$ & $2.8 * * *$ \\
\hline 336 & Transportation equipment & 7.4 & 5.9 & $1.7 *$ & 1.5 \\
\hline 337 & Furniture & 7.7 & 4.4 & $2.0 *$ & 1.5 \\
\hline 339 & $\begin{array}{l}\text { Miscellaneous } \\
\text { manufacturing }\end{array}$ & 10.0 & .0 & $2.0 *$ & .1 \\
\hline
\end{tabular}

Notes:

Regressions run from 1974 to 2001.

* significant at the 10 percent level, ${ }^{* *}$ significant at the 5 percent level, ${ }^{* * *}$ significant at the 1 percent level.

The high-technology industries include computers, communications equipment, and semiconductors (NAICS 3341, 3342, 334412-9). 
Table 6. Predicting the Change in Capacity by Lagged Utilization Rates

\begin{tabular}{|c|c|c|c|}
\hline \multirow[b]{2}{*}{ NAICS } & \multirow[b]{2}{*}{ Industry } & \multicolumn{2}{|c|}{$\begin{array}{c}t \text {-statistic on } \\
\text { lagged utilization }\end{array}$} \\
\hline & & FRB & $\mathrm{SPC}$ \\
\hline & Manufacturing & $1.7 *$ & -.9 \\
\hline & Excluding high-tech industries & $3.3 * * *$ & -.0 \\
\hline 311 & Food & $2.2 * *$ & $1.9^{*}$ \\
\hline 312 & Beverage and tobacco & -.5 & $2.1 * *$ \\
\hline 313 & Textile mills & $2.7 * *$ & 1.6 \\
\hline 314 & Textile product mills & $2.9 * * *$ & $1.8^{*}$ \\
\hline 315 & Apparel & $2.2 * * *$ & $3.1 * * *$ \\
\hline 316 & Leather & $2.4 * * *$ & .6 \\
\hline 321 & Wood products & $4.1 * * *$ & $2.1 * *$ \\
\hline 322 & Paper & $3.1 * * *$ & $2.2 * *$ \\
\hline 323 & Printing & .8 & $1.7^{*}$ \\
\hline 324 & Petroleum and coal products & $2.6^{* *}$ & $2.9 * *$ \\
\hline 325 & Chemicals & $1.7^{*}$ & -.5 \\
\hline 326 & Plastics and rubber products & $4.2 * * *$ & .8 \\
\hline 327 & Nonmetallic minerals & $4.6 * * *$ & 1.5 \\
\hline 331 & Primary metals & $7.7 * * *$ & $2.6^{* *}$ \\
\hline 332 & Fabricated metal products & $4.2 * * *$ & 1.3 \\
\hline 333 & Machinery & $4.5^{* * *}$ & .7 \\
\hline 334 & Computer and electronic product & -1.1 & $-2.7 * *$ \\
\hline 335 & Electrical equipment and appliances & $3.5 * * *$ & .2 \\
\hline 336 & Transportation equipment & $2.0 *$ & 1.0 \\
\hline 337 & Furniture & 1.4 & -.5 \\
\hline 339 & Miscellaneous manufacturing & $1.9^{*}$ & -.9 \\
\hline
\end{tabular}

Notes:

Regressions run from 1974 to 2002.

* significant at the 10 percent level, ${ }^{* *}$ significant at the 5 percent level, *** significant at the 1 percent level.

The high-technology industries include computers, communications equipment, and semiconductors (NAICS 3341, 3342, 334412-9). 
Table 7. Predicting the Change in Industry Price Inflation by Lagged Utilization Rates

\begin{tabular}{|c|c|c|c|}
\hline \multirow[b]{2}{*}{ NAICS } & \multirow[b]{2}{*}{ Industry } & \multicolumn{2}{|c|}{$\begin{array}{c}t \text {-statistic on } \\
\text { lagged utilization }\end{array}$} \\
\hline & & FRB & $\mathrm{SPC}$ \\
\hline & Manufacturing & $2.2 * *$ & $2.2 * *$ \\
\hline 311 & Food & .3 & -.8 \\
\hline 312 & Beverage and tobacco & $2.6 * *$ & -.6 \\
\hline 313 & Textile mills & $3.0 * * *$ & $3.1 * * *$ \\
\hline 314 & Textile product mills & $1.8^{*}$ & 1.5 \\
\hline 315 & Apparel & -.3 & -.5 \\
\hline 316 & Leather & $-1.8 *$ & -.5 \\
\hline 321 & Wood products & -.9 & -1.3 \\
\hline 322 & Paper & $1.9 *$ & 1.1 \\
\hline 323 & Printing & $2.7 * *$ & .6 \\
\hline 324 & Petroleum and coal products & 1.1 & 1.0 \\
\hline 325 & Chemicals & .9 & -.2 \\
\hline 326 & Plastics and rubber products & $2.2 * *$ & 1.1 \\
\hline 327 & Nonmetallic minerals & .2 & $1.7^{*}$ \\
\hline 331 & Primary metals & -.1 & -.1 \\
\hline 332 & Fabricated metal products & $2.7 * *$ & $2.2^{* *}$ \\
\hline 333 & Machinery & $1.9 *$ & 1.3 \\
\hline 334 & Computer and electronic product & -1.0 & .8 \\
\hline 335 & Electrical equipment and appliances & $2.5^{* *}$ & $2.6 * *$ \\
\hline 336 & Transportation equipment & -.2 & -.1 \\
\hline 337 & Furniture & $2.4^{* *}$ & 1.4 \\
\hline 339 & Miscellaneous manufacturing & $2.0^{*}$ & 1.3 \\
\hline
\end{tabular}

Notes:

Regressions run from 1974 to 2002.

* significant at the 10 percent level, ** significant at the 5 percent level, *** significant at the 1 percent level. 


\section{Figure 1. Capacity Utilization and Capacity}

\section{Capacity utilization}

(fourth quarter, percent of output)

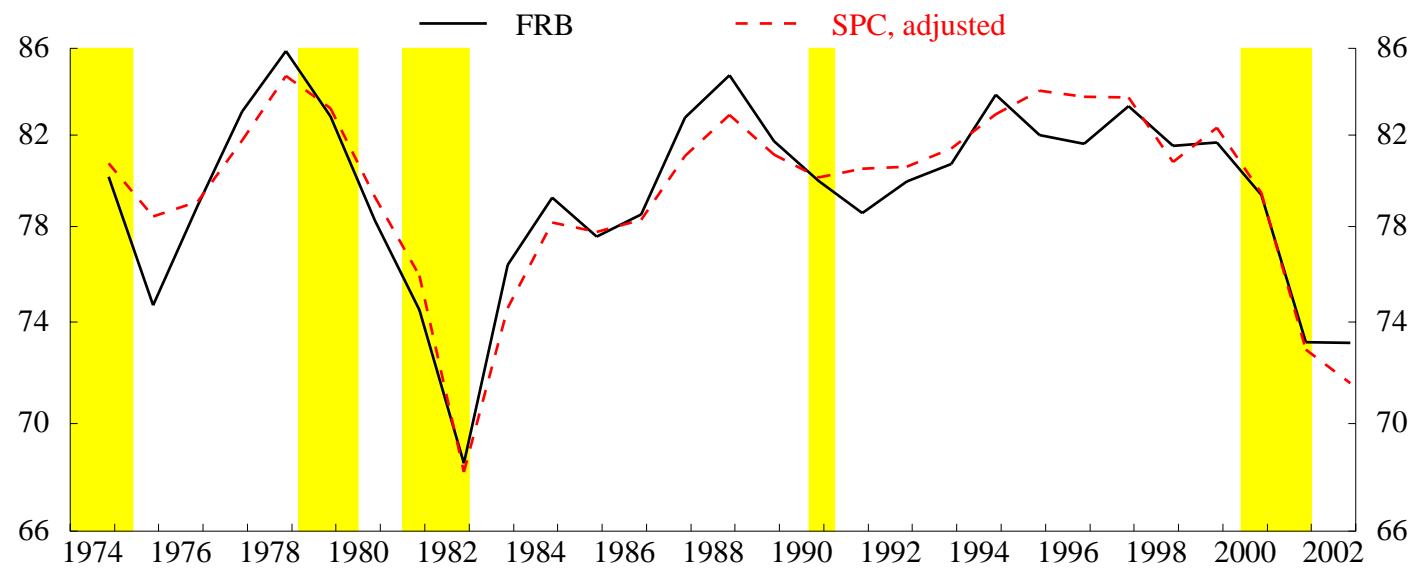

\section{Implied capacity}

(fourth quarter, percent of 1997 output)

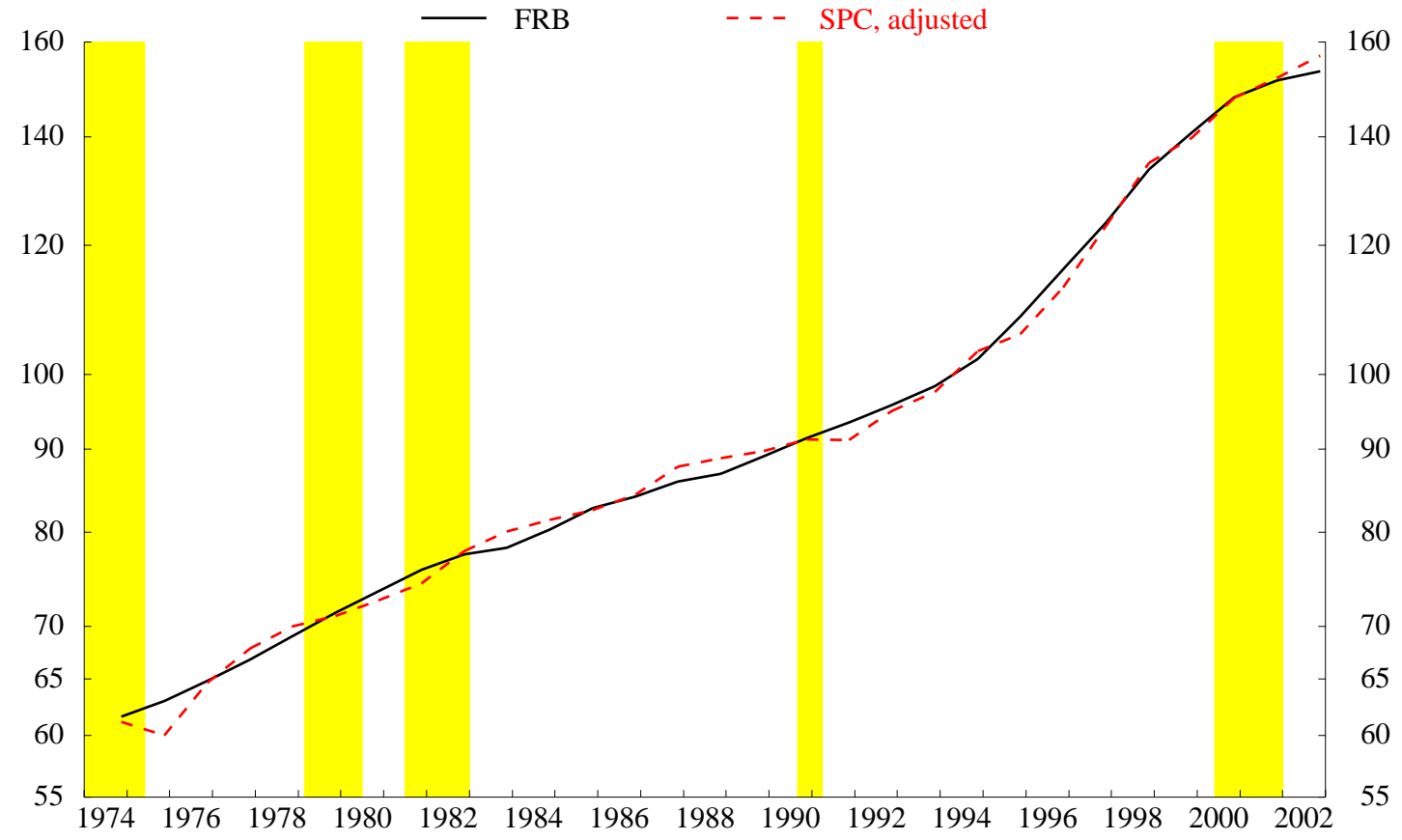

Adjusted: mean difference between the SPC and FRB rates removed, and the level shift after 1994 dummied out The shaded areas represent periods between the peaks and toughs in total industrial production. 